\begin{tabular}{|c|c|}
\hline Title & $\begin{array}{l}\text { Effects of Dosage Increase on Electrical Properties of Metal-Oxide Semiconductor Diodes with Mg-Ion-Implanted GaN } \\
\text { Before A ctivation A nnealing }\end{array}$ \\
\hline Author(s) & A kazawa, Masamichi; Kamoshida, Ryo; Murai, Shunta; Narita, Tetsuo; Omori, Masato; Suda, Jun; Kachi, Tetsu \\
\hline Citation & $\begin{array}{l}\text { Physica status solidi B-basic solid state physics, 257(2), } 1900367 \\
\text { https://doi.org/10.1002/pssb.201900367 }\end{array}$ \\
\hline Issue Date & $2020-02-06$ \\
\hline Doc URL & http:/hdl.handle.net/2115/80376 \\
\hline Rights & $\begin{array}{l}\text { This is the peer reviewed version of the following article: A kazawa, M. Kamoshida, R., Murai, S. , Narita, T. , Omori, } \\
\text { M., Suda, J. and Kachi, T. (2019), Effects of Dosage Increase on Electrical Properties of Metal- Oxide- } \\
\text { Semiconductor Diodes with Mg- Ion- Implanted GaN Before A ctivation A nnealing. Phys. Status Solidi B., which has } \\
\text { been published in final form at https://doi.org/10.1002/pssb.201900367. This article may be used for non-commercial } \\
\text { purposes in accordance with Wiley Terms and Conditions for U se of Self-A rchived Versions. }\end{array}$ \\
\hline Type & article (author version) \\
\hline File Information & pssb201900367_for printing.pdf \\
\hline
\end{tabular}

Instructions for use 


\section{Effects of dosage increase on electrical properties of metal-oxide- semiconductor diodes with Mg-ion-implanted GaN before activation annealing}

Masamichi Akazawa ${ }^{1 *}$, Ryo Kamoshida ${ }^{1}$, Shunta Murai ${ }^{1}$, Tetsuo Narita ${ }^{2}$, Masato Omori $^{3}{ }^{[+]}$, Jun Suda ${ }^{3,4}$ and Tetsu Kachi ${ }^{3}$

${ }^{1}$ Research Center for Integrated Quantum Electronics, Hokkaido University, Sapporo 060-0813, Japan

${ }^{2}$ Toyota Central R\&D Labs., Inc., Yokomichi, Nagakute 480-1192, Japan

${ }^{3}$ Institute of Materials and Systems for Sustainability, Nagoya University, Nagoya 464-8601, Japan

${ }^{4}$ Department of Electronics, Nagoya University, Nagoya 464-8603, Japan

${ }^{[+}$Present address: Department of Innovative Engineering, Oita University, Oita 870-1192, Japan

”E-mail: akazawa@rciqe.hokudai.ac.jp

Keywords: GaN, MOS, deep level, Mg-ion implantation

The effect of increasing the dosage on the electrical properties of Mg-ion-implanted GaN before activation annealing is investigated to obtain knowledge on the defect levels generated by ion implantation. To probe the near-surface region, GaN MOS structures with $\mathrm{Al}_{2} \mathrm{O}_{3}$ were used. Two kinds of MOS diodes with Mg-ion dosages of $1.5 \times 10^{11} \mathrm{~cm}^{-2}$ and $1.5 \times 10^{12} \mathrm{~cm}^{-2}$ implanted at $50 \mathrm{keV}$ were prepared. Although anomalous capacitance-voltage $(C-V)$ characteristics were observed for the low-dosage sample, they were improved by annealing at $600{ }^{\circ} \mathrm{C}$ for $3 \mathrm{~h}$. However, for the high-dosage sample, more severe and persistent frequency dispersion was observed in the $C-V$ characteristics, which was not improved by the same annealing. On the basis of the detailed analysis of capacitance-frequency $(C-f)$ characteristics, it is concluded that the discrete interface trap at $0.2-0.3 \mathrm{eV}$ below the conduction band was responsible for the frequency dispersion observed for the high-dosage sample. Combined with the results of deeplevel transient spectroscopy, it is highly likely that the bulk deep levels affected the $C-V$ and $C-f$ characteristics. The possibility that the dominant deep levels were changed by the increase in Mg-ion dosage is discussed. 


\section{WILEY-VCH}

\section{Introduction}

GaN has a high electron saturation velocity and a high breakdown voltage and can form a heterostructure with other III-nitride alloys ${ }^{[1]}$. With these features, recent attention has focused on the application of $\mathrm{GaN}$ to power devices ${ }^{[2,3]}$, although this material was behind the revolution in the efficiency of light-emitting diodes and has contributed to energy conservation ${ }^{[4,5]}$. A timely report on an excellent property of an $\mathrm{Al}_{2} \mathrm{O}_{3} / \mathrm{GaN}$ on $\mathrm{GaN}$ interface formed by atomic layer deposition (ALD) is available ${ }^{[6,7]}$ and enhanced the applicability of GaN being expanded to power devices, i.e., metal-oxide-semiconductor field effect transistors (MOSFETs). In particular, a vertical MOSFET is a useful power device for achieving a high breakdown voltage and a low on-resistance ${ }^{[3,8-10]}$. To construct power devices, including vertical MOSFETs, ion implantation is a convenient method of obtaining a selectively doped region. Although the formation of the n-type region can be practically accomplished by $\mathrm{Si}$-ion implantation, that of the p-type region has been difficult by ion implantation. Although the most promising method for implanting acceptors is $\mathrm{Mg}$-ion implantation, satisfactory doping control of $\mathrm{Mg}$ acceptors is difficult to achieve.

Recently, attempts have been made to achieve sufficient activation of implanted $\mathrm{Mg}$ acceptors $^{[11-18]}$. Commonly, activation is achieved by thermal annealing at a temperature higher than $1,200{ }^{\circ} \mathrm{C}$ or, more specifically, $1,230{ }^{\circ} \mathrm{C}^{[15,16]}$. The activation ratio should be defined as the ratio of the hole concentration to the acceptor density. Owing to an activation energy as high as $160 \mathrm{meV}^{[19-21]}$, the activation ratio decreases with increasing doping density of acceptors. Using symmetric multicycle rapid thermal annealing (SMRTA) in nitrogen overpressure, an activation ratio as high as $10 \%^{[14]}$ has been achieved, which agrees with the theoretical limit. However, the highest activation ratio of $2.3 \%^{[18]}$ achieved by conventional RTA is lower than the theoretical limit. In consideration of mass production, an efficient annealing method in an ordinary furnace must be established. For this purpose, defects generated by Mg-ion implantation should be investigated to find a control method.

Ion implantation can generate vacancies of gallium $V_{\mathrm{Ga}}$ and nitrogen $V_{\mathrm{N}}$. The results of positron annihilation spectroscopy (PAS) in the study of Mg-ion-implanted $\mathrm{GaN}^{[22,23]}$ showed that the divacancy $V_{\mathrm{Ga}}-V_{\mathrm{N}}$ is mainly generated by implantation at room temperature and that the agglomeration to form larger vacancy clusters proceeds upon annealing at $1,000{ }^{\circ} \mathrm{C}$. These vacancy clusters still existed even after annealing at $1,300{ }^{\circ} \mathrm{C}$. Nevertheless, a new clue to control the defects generated by Mg-ion implantation might be found by applying lowtemperature annealing. Recently, it was reported that annealing at $800{ }^{\circ} \mathrm{C}$ for $3 \mathrm{~min}$ after $\mathrm{Mg}$ ion implantation reduced the density of the deep-level states in lightly Mg-ion-implanted 


\section{WILEY-VCH}

$\mathrm{GaN}^{[24]}$. A detailed deep-level transient spectroscopy (DLTS) study has been conducted to investigate the effect of low-temperature annealing for $1 \mathrm{~min}$ on defects generated by Mg-ion implantation at a low dosage ${ }^{[25]}$. Very recently, the effect of low-temperature annealing was also monitored using MOS diodes with Mg-ion implanted GaN for the case of relatively low dosage, to find that $500-700{ }^{\circ} \mathrm{C}$ annealing for 3 min was efficient to improve the electrical properties of ion-implanted $\mathrm{GaN}^{[26]}$. However, these electrical measurements were performed on lowdosage GaN samples. The effect of increasing the dosage has not been investigated. In this work, we studied the effects of increasing the dosage on the electrical properties of MOS diodes with Mg-ion-implanted GaN before activation annealing.

\section{Experimental procedure}

In this work, GaN MOS structures with $\mathrm{Al}_{2} \mathrm{O}_{3}$ were used to investigate the near-surface region of Mg-ion-implanted GaN. The sequence of sample preparation is shown in Figure 1. A 3- $\mu \mathrm{m}-$ thick n-type GaN layer $\left(n=5 \times 10^{17} \mathrm{~cm}^{-3}\right)$ was grown on a freestanding c-plane $n^{+}$-GaN substrate (the dislocation density of the freestanding substrate was lower than $5.0 \times 10^{6} \mathrm{~cm}^{-2}$ ) by metalorganic vapor phase epitaxy. Mg-ion implantation was carried out with an energy of 50 $\mathrm{keV}$ and an angle of $7^{\circ}$ at room temperature. A sample with a dosage of $1.5 \times 10^{11} \mathrm{~cm}^{-2}$ and another with a dosage of $1.5 \times 10^{12} \mathrm{~cm}^{-2}$ were prepared. Figure 2 is a plot of the $\mathrm{Mg}$ density profile obtained by the TRIM simulation in the full cascade calculation mode with displacement energies of $28 \mathrm{eV}$ and $25 \mathrm{eV}$ for $\mathrm{N}$ and Ga, respectively. For samples with long-term $600{ }^{\circ} \mathrm{C}$ annealing, a 20-nm-thick $\mathrm{Al}_{2} \mathrm{O}_{3}$ layer was deposited by $\mathrm{ALD}$ at $300{ }^{\circ} \mathrm{C}$ using $\mathrm{H}_{2} \mathrm{O}$ and trimethylaluminum, followed by annealing at $600{ }^{\circ} \mathrm{C}$ for $3 \mathrm{~h}$ in nitrogen flow and subsequent removal of the $\mathrm{Al}_{2} \mathrm{O}_{3}$ layer using a solution of $\mathrm{HF}: \mathrm{NH}_{4} \mathrm{~F}=1: 5$. A MOS diode structure was fabricated by depositing 30-nm-thick $\mathrm{ALD} \mathrm{Al}_{2} \mathrm{O}_{3}$ and forming $\mathrm{Ni} / \mathrm{Au}$ top electrodes and a $\mathrm{Ti} / \mathrm{Au}$ back ohmic contact. After completion of the MOS diodes, post-metallization annealing (PMA) was carried out to reduce the density of interface states at the $\mathrm{Al}_{2} \mathrm{O}_{3} / \mathrm{GaN}$ interface. For comparison, samples without long-term $600{ }^{\circ} \mathrm{C}$ annealing and a sample with as-grown $\mathrm{GaN}$ without Mg-ion implantation were also prepared.

The capacitance-voltage $(C-V)$ and capacitance-frequency $(C-f)$ measurements at frequencies ranging from $1 \mathrm{kHz}$ to $1 \mathrm{MHz}$ and the current density-voltage $(J-V)$ measurement were performed at room temperature. The bias sweep rate in the $C-V$ measurement was 50 $\mathrm{mV} / \mathrm{s}$. DLTS was also carried out in the temperature range of $40-560 \mathrm{~K}$ for the same MOS diodes. Since the dosage of $\mathrm{Mg}$ ions is relatively low here, there is a possibility that popular structural and chemical analysis methods such as atomic force microscopy, X-ray diffraction, 


\section{WILEY-VCH}

and X-ray photoelectron spectroscopy may not reveal the effect of Mg-ion implantation. Nevertheless, electrical measurements make it possible to investigate the effect of low-dosage Mg-ion implantation in GaN. Therefore, we concentrated on the electrical measurements. An investigation of a sample with a much higher dosage is beyond the scope of this paper.

\section{Results and discussion}

\section{1. $J-V$ and $C-V$ characteristics}

The measured $J-V$ characteristics are summarized and compared in Figure 3 for all of the fabricated MOS diodes. Relatively low $J$ was obtained in the entire applied voltage range for each sample. This result indicates that every MOS diode can be used for the $C-V$ measurement without any adverse effect of the leakage current. Lower $J$ for the high-dosage samples in the plus bias region may result from deep depletion, while higher $J$ for the as-grown and the lowdosage samples may indicate the achievement of surface accumulation in the same bias region. These expectations were confirmed by the $C-V$ measurement as described in the following.

Figure 4(a) shows the $C-V$ characteristics measured for the MOS diode with as-grown $\mathrm{GaN}$ without $\mathrm{Mg}$-ion implantation. The $C-V$ curves almost overlap the ideal one assuming no interface states. In addition, the frequency dispersion and the hysteresis are negligible. This result indicates that the interface state density was extremely low at the $\mathrm{Al}_{2} \mathrm{O}_{3} / \mathrm{GaN}$ interface and that bulk deep levels with concentrations sufficient to affect the $C-V$ characteristics did not exist in the as-grown GaN epitaxial layer. Figure 4(b) shows the $C-f$ characteristics measured for the same sample. As is expected from the $C-V$ characteristics, flat capacitance curves can be seen. These results are starting points for investigating the $C-V$ and $C-f$ characteristics.

The $C-V$ characteristics measured for the sample with the lower dosage are shown in Figure 5, where the ideal curve is the theoretical curve assuming no interface states for the MOS diode with the as-grown $\mathrm{GaN}$ without $\mathrm{Mg}$-ion implantation. Without long-term $600{ }^{\circ} \mathrm{C}$ annealing, the $C-V$ curves show anomalous shapes compared with the ideal curve, as shown in Figure 5(a). The plateau region and anomalously steep region indicate the existence of an acceptor-type discrete state in the band gap, as discussed in detail in the previous work ${ }^{[24,26]}$. Note that the anomalous behavior was much improved by long-term $600{ }^{\circ} \mathrm{C}$ annealing, as shown in Figure 5(b), where the hysteresis and frequency dispersion are minimized without showing a plateau region. This result shows that the dominant defect level was greatly reduced by longterm $600{ }^{\circ} \mathrm{C}$ annealing. In the previous work ${ }^{[26]}$, although annealing at $400{ }^{\circ} \mathrm{C}$ for 3 min was applied to the low-dosage sample made by the same process sequence including ALD and the removal of $\mathrm{Al}_{2} \mathrm{O}_{3}$, the $C-V$ characteristics were not improved. Therefore, ALD and the removal 


\section{WILEY-VCH}

of $\mathrm{Al}_{2} \mathrm{O}_{3}$ before and after long-term $600{ }^{\circ} \mathrm{C}$ annealing of the present sample do not improve the discrete state.

The $C-V$ characteristics were changed by increasing the dosage by one order and the effect of annealing was less marked for the high-dosage sample. Figure 6(a) shows the $C-V$ characteristics for the high-dosage sample without long-term $600{ }^{\circ} \mathrm{C}$ annealing. Severe frequency dispersion can be seen in the relatively high frequency range of $1 \mathrm{kHz}$ to $1 \mathrm{MHz}$. This behavior was not significantly improved by long-term $600{ }^{\circ} \mathrm{C}$ annealing, as shown in Figure 6(b). The difference between the capacitances measured at $100 \mathrm{kHz}$ and $1 \mathrm{MHz}$ is the widest among the measured frequencies, which suggests the existence of a deep level at an energy level near the conduction band edge $E_{\mathrm{C}}$. On the other hand, the considerable hysteresis in both Figure 6(a) and 6(b) indicates the existence of another deep level with a longer time constant or a deeper energy position. Although we have not performed higher temperature annealing, we consider it a future work.

As was discussed in the previous work ${ }^{[26]}$, the $C-V$ characteristics for the low-dosage samples can be explained by the existence of a deep level at $E_{\mathrm{C}}-0.7 \mathrm{eV}$. However, this energy level has a time constant $\tau$ of $8.6-860 \mathrm{~s}$ if we assume the capture cross section $\sigma$ to be $1 \times 10^{-17}-1 \times 10^{-}$ ${ }^{15} \mathrm{~cm}^{2}$ in the equation given by ${ }^{[25,27,28]}$

$$
\tau=\frac{1}{\sigma v_{t h} N_{C}} \exp \left(\frac{E_{C}-E_{T}}{k T}\right)
$$

where $v_{\text {th }}$ is the electron thermal velocity, $N_{\mathrm{C}}$ is the effective density of states at the conduction band bottom, $E_{\mathrm{T}}$ is the energy of the deep level, $k$ is the Boltzmann constant, and $T$ is the temperature. Therefore, the existence of the deep level at $E_{\mathrm{C}}-0.7 \mathrm{eV}$ cannot explain the observed frequency dispersion for the high-dosage sample, although it well explains the behavior of the hysteresis for both samples. This implies the existence of a shallower deep level in the high dosage sample. Nevertheless, there is also a possibility that the interface states caused the frequency dispersion. To distinguish this, $C-f$ measurement was carried out as described in the following subsection.

\subsection{Analysis of $C-f$ characteristics}

The $C-f$ characteristics measured for the high-dosage sample without long-term $600{ }^{\circ} \mathrm{C}$ annealing are shown in Figure 7(a). It can be seen that the frequency dependent $C-f$ curve shifts with the bias. However, the relaxation frequency of each $C-f$ curve with the conductance, $G / \omega$, peak seems to saturate as the bias voltage increases. As shown in Figure 5(b), a slight change 


\section{WILEY-VCH}

in the $C-f$ characteristics was observed for the high-dosage sample with long-term $600{ }^{\circ} \mathrm{C}$ annealing. Nevertheless, the behavior of the relaxation frequency is similar to the case without long-term $600{ }^{\circ} \mathrm{C}$ annealing, indicating saturation with increasing bias.

The observed frequency dispersion is likely caused by interface traps. To investigate the time constant of the interface traps, let us transform the equivalent circuit for measured data to that for the physical model of the MOS diode. Figure 8(a) shows the equivalent circuit used in the $C-V$ and $C-f$ measurements consisting of the measured capacitance $C_{\mathrm{m}}$ and conductance $G_{\mathrm{m}}$, while Figure $8(\mathrm{~b})$ indicates that for the physical model of a MOS diode with oxide capacitance $C_{\mathrm{O}}$, depletion layer capacitance $C_{\mathrm{D}}$, and the interface trap admittance consisting of frequency dependent capacitance $C_{\mathrm{p}}$ and frequency dependent conductance $G_{\mathrm{p}}$. Here, $C_{\mathrm{p}}$ and $G_{\mathrm{p}}$ can be calculated by ${ }^{[29-31]}$

$$
C_{p}=\frac{\left\{\left(C_{O X}-C_{m}\right) C_{m}-\left(G_{m} / \omega\right)^{2}\right\} C_{O X}}{\left(G_{m} / \omega\right)^{2}+\left(C_{O X}-C_{m}\right)^{2}}-C_{D}
$$

and

$$
\frac{G_{p}}{\omega}=\frac{C_{O X}^{2}\left(G_{m} / \omega\right)}{\left(G_{m} / \omega\right)^{2}+\left(C_{O X}-C_{m}\right)^{2}} .
$$

According to the results of the calculation using these equations, $G_{\mathrm{p}} / \omega-C_{\mathrm{p}}$ diagrams, referred to as "Cole-Cole diagrams" ${ }^{[32,33]}$ are plotted in Figure 9 where the solid circles indicate the experimental data and solid lines indicate fitting lines assuming a single time constant. If the time constant of the interface traps is single, the equivalent circuit for the interface trap admittance can be drawn by a series connection of a frequency independent capacitance, $C_{\mathrm{it}}$, and a frequency independent resistance, $R_{\mathrm{it}}$, both of which are constants. For this case, $C_{\mathrm{p}}$ and $G_{\mathrm{p}} / \omega$ can be given by

$$
C_{p}=\frac{1}{1+\omega^{2} \tau^{2}} C_{i t}
$$

and

$$
\frac{G_{p}}{\omega}=\frac{\omega \tau}{1+\omega^{2} \tau^{2}} C_{i t}
$$


where $\tau=C_{\mathrm{it}} R_{\mathrm{it}}$. These equations indicate that a $G_{\mathrm{p}} / \omega-C_{\mathrm{p}}$ diagram should be a semicircle, as given by

$$
\left(C_{p}-\frac{C_{i t}}{2}\right)^{2}+\left(\frac{G_{p}}{\omega}\right)^{2}=\left(\frac{C_{i t}}{2}\right)^{2}
$$

In Figure 9, the fitting lines are semicircles calculated using Equation (6). It can be seen that the experimental data are well fitted to the calculated semicircles, especially for the high-dosage sample without long-term $600{ }^{\circ} \mathrm{C}$ annealing. Generally, Cole-Cole diagrams for the interface trap admittance of MOS diodes have distorted shapes far from a semicircle because of the distribution of the time constant resulting from the continuous distribution of the interface traps $^{[33]}$. Therefore, it is highly likely that each measured interface trap admittance mainly results from a discrete deep level with a single time constant. The discrepancy from the semicircles at the right side, that is, the low-frequency side, indicates the existence of deeper levels, although further investigation is limited by the low-frequency limit of the measurement system. $C_{\text {it }}$ and $\tau$ can be obtained by fitting the experimental $G_{\mathrm{p}} / \omega-f$ plot to Equation (5), which leads to the extraction of interface trap density $D_{\text {it }}$ as ${ }^{[31]}$

$$
D_{i t}=\frac{C_{i t}}{q^{2}}
$$

The experimentally extracted $G_{\mathrm{p}} / \omega-f$ plots are shown in Figure 10(a) for the high-dosage sample without $600{ }^{\circ} \mathrm{C}$ annealing and in Figure 10(b) for the high-dosage sample with $600{ }^{\circ} \mathrm{C}$ annealing. In these figures, the experimental data (solid circles) are well fitted to the theoretical curves calculated by Equation (5). The energy position of the interface traps can be obtained from $\tau$ at the peak frequency using Equation (1). If we assume $\sigma$ to be $1 \times 10^{-17} \mathrm{~cm}^{2}, 1 \times 10^{-16} \mathrm{~cm}^{2}$, and $1 \times 10^{-15} \mathrm{~cm}^{2}$, we can plot $D_{\text {it }}$ as a function of the energy position, as shown in Figure 11 . The extracted $D_{\mathrm{it}}$ distribution clearly indicates the existence of a discrete trap around $E_{\mathrm{C}}-E=$ $0.2-0.3 \mathrm{eV}$. This type of $D_{\mathrm{it}}$ distribution is unusual. According to the disorder-induced gap state model ${ }^{[34,35]}$, interface disorder is the origin of the interface states with a U-shaped continuous $D_{\text {it }}$ distribution consisting of the tails from the conduction and valence bands resulting from the incomplete separation of these bands. Actually, U-shaped $D_{\text {it }}$ distribution has been measured for insulator/GaN interfaces ${ }^{[6]}$. Therefore, the detected discrete interface trap should have resulted from the bulk deep level generated by Mg-ion implantation in GaN. 


\section{WILEY-VCH}

\subsection{Investigation of bulk deep levels}

To confirm the existence of the bulk deep levels, DLTS was performed for the fabricated MOS diodes without $600{ }^{\circ} \mathrm{C}$ annealing. The applied reverse voltage and the maximum voltage during the filling pulse were $-10 \mathrm{~V}$ and $1 \mathrm{~V}$ for the as-grown sample, $-5 \mathrm{~V}$ and $-2 \mathrm{~V}$ for the low-dosage sample, and $0 \mathrm{~V}$ and $2 \mathrm{~V}$ for the high-dosage sample, respectively. For the GaN-on-GaN MOS diode with $\mathrm{ALD} \mathrm{Al}_{2} \mathrm{O}_{3}$ treated by PMA, the stress-dependent flat band voltage shift was reported to be negligible, even after bias stress at $5 \mathrm{~V}$, in Ref. 6 . Considering the maximum voltage during the filling pulse was $2 \mathrm{~V}$ here, the flat band voltage shift should have been negligible. The obtained DLTS signals are shown in Figure 12(a) for the low-dosage sample and in Figure 12(b) for the high-dosage sample. It can be seen that the increase in dosage led to an increase in the signal intensity of level A. Level B was detected for the low-dosage sample, while level $\mathrm{C}$ was detected for the high-dosage sample. Arrhenius plots are summarized in Figure 13 where the result for the as-grown n-GaN layer without implantation is also shown and the dashed lines were taken from the previous reports as reference data. Level A was either undetected or under the detection limit for the as-grown sample. The level detected for the asgrown sample can be identified as E3 in Ref. 36. Deep level B at $E_{\mathrm{C}}-0.83 \mathrm{eV}$ with $\sigma$ of $1.8 \times 10^{-}$ ${ }^{15} \mathrm{~cm}^{2}$ detected for the low-dosage sample is clearly different from the E3 level detected for the as-grown sample, indicating that another level was generated by Mg-ion implantation. This result is in good agreement with the previous report ${ }^{[25]}$. In addition, this energy level is close to that derived by the simulation of $C-V$ characteristics of the low-dosage sample in the previous works $^{[24,26]}$. The energy position and $\sigma$ of level A were $E_{\mathrm{C}}-0.18 \mathrm{eV}$ and $4.5 \times 10^{-17} \mathrm{~cm}^{2}$ for the low-dosage sample, while they were $E_{\mathrm{C}}-0.19 \mathrm{eV}$ and $8.0 \times 10^{-17} \mathrm{~cm}^{2}$ for the high-dosage sample, respectively. On the basis of the Arrhenius plot, this level is probably the E1 level in Ref. 36 rather than $V_{\mathrm{N}}{ }^{[37]}$. The Arrhenius plot of deep level $\mathrm{C}$ at $E_{\mathrm{C}}-0.51 \mathrm{eV}$ with $\sigma$ of $4.8 \times 10^{-17} \mathrm{~cm}^{2}$ is close to the E3 level, which may be identified as E3. However, since $\sigma$ of deep level C is much smaller than that of E3 $\left(1.1 \times 10^{-15} \mathrm{~cm}^{2}\right)$, the possibility that level $\mathrm{C}$ was generated by $\mathrm{Mg}$ ion implantation cannot be denied.

For the high-dosage sample, the deep level at $E_{\mathrm{C}}-0.2$ to $E_{\mathrm{C}}-0.3 \mathrm{eV}$ was derived from the $C-f$ measurement. As the dosage increased, the dominance of this deep level became more marked in the $C-f$ characteristics, while the DLTS signal of deep level A became more intense. Therefore, the discrete level detected by the $C-f$ measurement is likely to be identified as level A. The origin of level A can be assigned to the divacancy $V_{\mathrm{Ga}}-V_{\mathrm{N}}[36,38-40]$. According to the PAS results, the divacancy is the dominant defect in as-implanted GaN, which is in good agreement 


\section{WILEY-VCH}

with the present result for the high-dosage sample. On the other hand, for the low-dosage sample, the dominant deep level, B, was detected at $E_{\mathrm{C}}-0.83 \mathrm{eV}$, which is also in good agreement with the previous reports ${ }^{[24-26]}$. In Ref. 26 , a possible mechanism was discussed, in which $V_{\mathrm{Ga}}$ and $V_{\mathrm{N}}$ exist separately in the low-dosage sample, while the divacancy is mainly formed in a sample with a higher dosage. However, the Arrhenius plots in Figure 13 indicate that level B detected for the low-dosage sample is different from E3 that can be assigned to the nitrogen antisite $N_{\mathrm{Ga}}$ or $V_{\mathrm{Ga}}{ }^{[36,40,41]}$. Therefore, level B should be assigned to a deeper level, e.g., nitrogen interstitial $\mathrm{N}_{i}$ acceptor ${ }^{[41]}$. It is reported that $\mathrm{N}_{i}$ is annealed at $400{ }^{\circ} \mathrm{C}^{[42]}$, which does not contradict the present result. Therefore there is the possibility that the dominant defect changed depending on the dosage.

\section{Conclusions}

The effect of the dosage on the electrical properties of Mg-ion-implanted $\mathrm{GaN}$ was investigated using MOS diodes to obtain knowledge on the defect levels generated by ion implantation. Although anomalous $C-V$ characteristics were observed for the low-dosage $\left(1.5 \times 10^{11} \mathrm{~cm}^{-2}\right)$ sample, they were improved by $600{ }^{\circ} \mathrm{C}$ annealing for $3 \mathrm{~h}$. However, for the high-dosage $\left(1.5 \times 10^{12} \mathrm{~cm}^{-2}\right)$ sample, more sever and persistent frequency dispersion was observed in the $C$ $V$ characteristics, which was not improved by the same annealing. On the basis of the detailed analysis of $C-f$ characteristics, a discrete level with a single time constant was detected. Considering the possible range of the capture cross section, it was concluded that the discrete interface traps at $0.2-0.3 \mathrm{eV}$ below $E_{\mathrm{C}}$ were responsible for the frequency dispersion observed for the high-dosage sample. Combined with the results of DLTS, it is highly likely that the bulk deep level affected the $C-V$ and $C-f$ characteristics because a similar deep level was detected. In addition, a deep level at $E_{\mathrm{C}}-0.83 \mathrm{eV}$, generated by $\mathrm{Mg}$-ion implantation, was detected for the low-dosage sample. This energy level is close to that derived by the simulation of the $C-V$ characteristics of the low-dosage sample in the previous works ${ }^{[24,26]}$. Although this deep level was not detected for the high-dosage sample, a deep level at $E_{\mathrm{C}}-0.51 \mathrm{eV}$ was detected. The origin of the detected deep levels was discussed.

\section{Acknowledgments}

This research is supported by the Ministry of Education, Culture, Sports, Science and Technology (MEXT), Japan, through its "Program for research and development of nextgeneration semiconductor to realize energy-saving society." 


\section{WILEY-VCH}

\section{Conflict of Interest}

The authors declare no conflict of interest.

\section{References}

[1] D. Ueda, in Power GaN Devices (Eds: M. Meneghini, G. Meneghesso, and E. Zanoni), Springer, New York, NY 2017, Ch. 1.

[2] T. Kachi, Jpn. J. Appl. Phys. 2014, 53, 100210.

[3] H. Amano, Y Baines, E. Beam, M. Borga, T. Bouchet, P. R Chalker, M. Charles, K. J. Chen, N. Chowdhury, R. Chu, C. De Santi, M. M. De Souza, S. Decoutere, L. Di Cioccio, B. Eckardt, T. Egawa, P. Fay, J. J. Freedsman, L. Guido, O. Häberlen, G. Haynes, T. Heckel, D. Hemakumara, P. Houston, J. Hu, M. Hua, Q. Huang, A. Huang, S. Jiang, H Kawai, D. Kinzer, M. Kuball, A. Kumar, K. B. Lee, X. Li, D. Marcon, M. März, R. McCarthy, G. Meneghesso, M. Meneghini, E. Morvan, A. Nakajima, E. M. S. Narayanan, S. Oliver, T. Palacios, D. Piedra, M. Plissonnier, R. Reddy, M. Sun, I. Thayne, A. Torres, N. Trivellin, V. Unni, M. J. Uren, M. V. Hove, D. J. Wallis, J. Wang, J. Xie, S. Yagi, S. Yang, C. Youtsey, R. Yu, E. Zanoni, S. Zeltner, Yuhao Zhang, J. Phys. D, Appl. Phys. 2018, 51, 163001.

[4] H. Amano, M. Kito, K. Hiramatsu, I. Akasaki, Jpn. J. Appl. Phys. 1989, 28, L2112.

[5] S. Nakamura, T. Mukai, M. Senoh, Appl. Phys. Lett. 1994, 64, 1687.

[6] S. Kaneki, J. Ohira, S. Toiya, Z. Yatabe, J. T. Asubar, T. Hashizume, Appl. Phys. Lett. 2016, 109, 162104.

[7] K. Nishiguchi, S. Kaneki, S. Ozaki, T. Hashizume, Jpn. J. Appl. Phys. 2017, 56, 101001.

[8] T. Oka, T. Ina, Y. Ueno, J. Nishi, Appl. Phys. Express 2015, 8, 054101.

[9] D. Ji, A. Agwal, H. Li, W. Li, S. Keller, S. Chowdhury, IEEE Electron Dev. Lett. 2018, 39, 863.

[10] D. Ji, W. Li, A. Agwal, S. H. Chan, J. Haller, D. Bisi, M. Labrecque, C. Gupta, B. Cruse, R. Lal, S. Keller, U. K. Mishra, S. Chowdhury, IEEE Electron Dev. Lett. 2018, 39 , 1030.

[11] B. N. Feigelson, T. J. Anderson, M. Abraham, J. A. Freitas, J. K. Hite, C. R. Eddy, F. J. Kub, J. Cryst. Growth 2012, 350, 21.

[12] T. J. Anderson, B. N. Feigelson, F. J. Kub, M. J. Tadjer, K. D. Hobart, M. A. Mastro, J. K. Hite, C. R. Eddy, Electron. Lett. 2014, 50, 197.

[13] J. D. Greenlee, T. J. Anderson, B. N. Feigelson, K. D. Hobart, F. J. Kub, Phys. Status Solidi A 2015, 212, 2772.

[14] T. J. Anderson, J. D. Greenlee, B. N. Feigelson, J. K. Hite, K. D. Hobart, F. J. Kub, IEEE Trans. Semicond. Manuf. 2016, 29, 343. 


\section{WILEY-VCH}

[15] K. Nomoto, K. Takahashi, T. Oikawa, H. Ogawa, T. Nishimura, T. Mishima, H. G. Xing, T. Nakamura, ECS Trans. 2015, 69, 105.

[16] T. Oikawa, Y. Saijo, S. Kato, T. Mishima, T. Nakamura, Nuclear Instruments, Methods in Physics Research B 2015, 365, 168.

[17] T. Narita, T. Kachi, K. Kataoka, T. Uesugi, Appl. Phys. Exp. 2017, 10, 016501.

[18] T. Niwa, T. Fujii, T. Oka, Appl. Phys. Express 2017, 10, 091002.

[19] I. Akasaki, H. Amano, M. Kito, K. Hiramatsu, J. Lumin. 1991, 48 \& 49, 666.

[20] T. Tanaka, A. Watanabe, H. Amano, Y. Kobayashi, I. Akasaki, S. Yamazaki, M. Koike, Appl. Phys. Lett. 1994, 65, 593.

[21] W. Götz, N. M. Johnson, J. Walker, D. P. Bour, R. A. Street, Appl. Phys. Lett. 1996, $68,667$.

[22] A. Uedono, S. Takashima, M. Edo, K. Ueno, H. Matsuyama, H. Kudo, H. Naramoto, S. Ishibashi, Phys. Status Solidi B 2015, 252, 2794.

[23] A. Uedono, S. Takashima, M. Edo, K. Ueno, H. Matsuyama, W. Egger, T. Koschine, C. Hugenschmidt, M. Dickmann, K. Kojima, S.F. Chichibu, S. Ishibashi, Phys. Status Solidi B 2018, 255, 1700521.

[24] M. Akazawa, N. Yokota, K. Uetake, AIP Advances 2018, 8, 025310.

[25] G. Alfieri, V.K. Sundaramoorthy, R. Micheletto, J. Appl. Phys. 2018, 123, 205303.

[26] M. Akazawa, K. Uetake, Jpn. J. Appl. Phys. 2019, 58, SCCB10.

[27] P. Kamyczek, E. Placzek-Popko, E. Zielony, Z. Zytkiewicz, Material Science-Poland 2013, 31, 572 .

[28] P. Hacke, T. Detchprohm, K. Hiramatsu, N. Sawaki, K. Tadatomo, K. Miyake, J. Appl. Phys. 1994, 76, 304.

[29] E. H. Nicollian, J. R. Brews, MOS (Metal Oxide Semiconductor) Physics and Technology, Wiley, Hoboken, NJ, USA 2003, Ch. 5.

[30] W. A. Hill, C. C. Coleman, Solid-State Electronics 1980, 23, 987.

[31] S. M. Sze, K. K. Ng, Physics of Semiconductor Devices, 3rd edn, Wiley, Hoboken, NJ, USA 2007, Ch. 4.

[32] K. S. Cole, R. H. Cole, J. Chem. Phys. 1941, 9, 341.

[33] T. Sawada, H. Hasegawa, Phys. Status Solidi A 1979, 54, 689.

[34] H. Hasegawa, H. Ohno, J. Vac. Sci. \& Technol. B 1986, 4, 1130.

[35] H. Hasegawa, M. Akazawa, Appl. Surf. Sci 2008, 254, 8005.

[36] U. Honda, Y. Yamada, Y. Tokuda, K. Shiojima, Jpn. J. Appl. Phys. 2012, 51, 04 DF04.

[37] Z.-Q. Fang, D. C. Look, W. Kim, Z. Fan, A. Botchkarev, H. Morkoç, Appl. Phys. Lett. 


\section{WILEY-VCH}

1998, 72, 2277.

[38] Z.-Q. Fang, D. C. Look, X.-L. Wang, J. Han, F. A. Khan, I. Adesida, Appl. Phys. Lett. 2003, 82, 1562.

[39] Z.-Q. Fang, D. C. Look, D. H. Kim, I. Adesida, Appl. Phys. Lett. 2005, 87, 182115.

[40] Y. Tokuda, Y. Matsuoka, H. Ueda, O. Ishigro, N. Soejima, T. Kachi, Superlattice and Microstructures 2006, 40, 268.

[41] J. L. Lyons, C. G. Van de Walle, NPJ Computational Materials 2017, $12,1$.

[42] H. J. von Bardeleben, J. L. Cantin, U. Gerstmann, A. Scholle, S. Greulich-Weber, E. Rauls, M. Landmann, W. G. Schmidt, A. Gentils, J. Botsoa, M. F. Barthe, Phys. Rev. Lett. 2012, 109, 206402. 


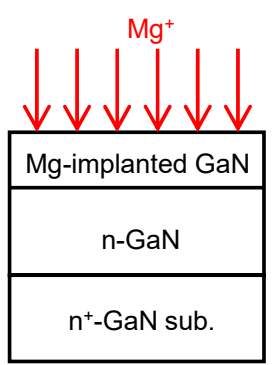

Mg-ion implantation

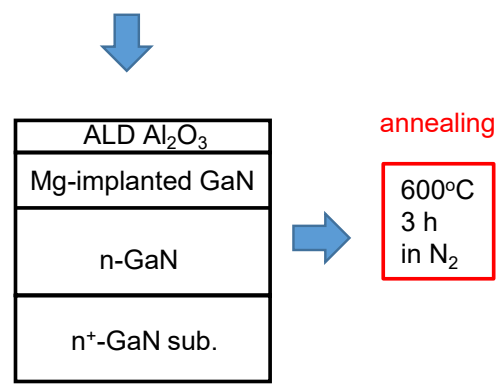

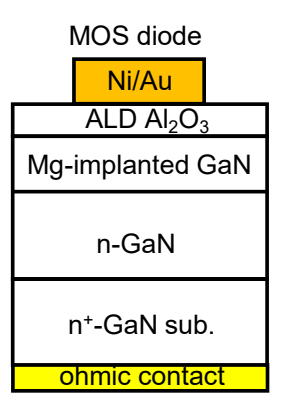

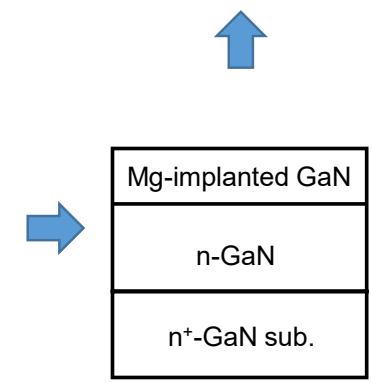

Figure 1. Fabrication sequence for tested GaN MOS diodes.

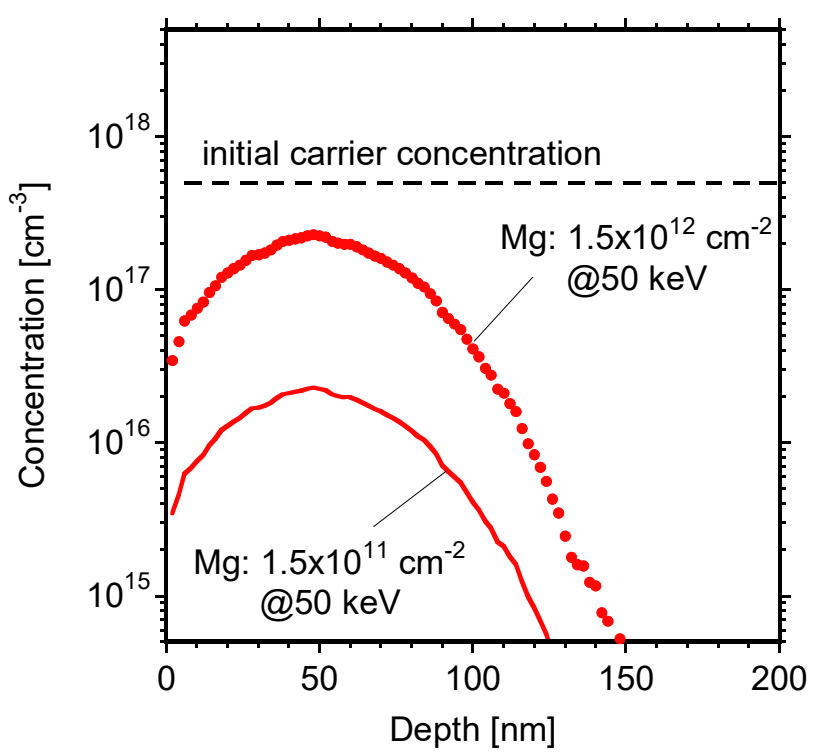

Figure 2. TRIM simulation results of $\mathrm{Mg}$ concentration in $\mathrm{GaN}$ for two cases of $\mathrm{Mg}$-ion implantation with different dosages. 


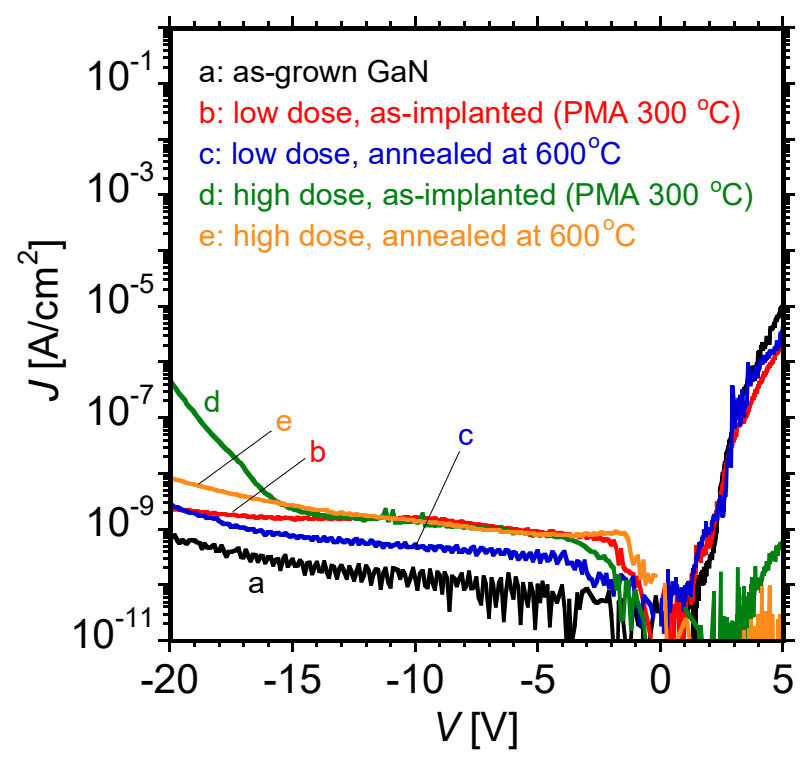

Figure 3. Summary of $J-V$ characteristics measured for all samples. 

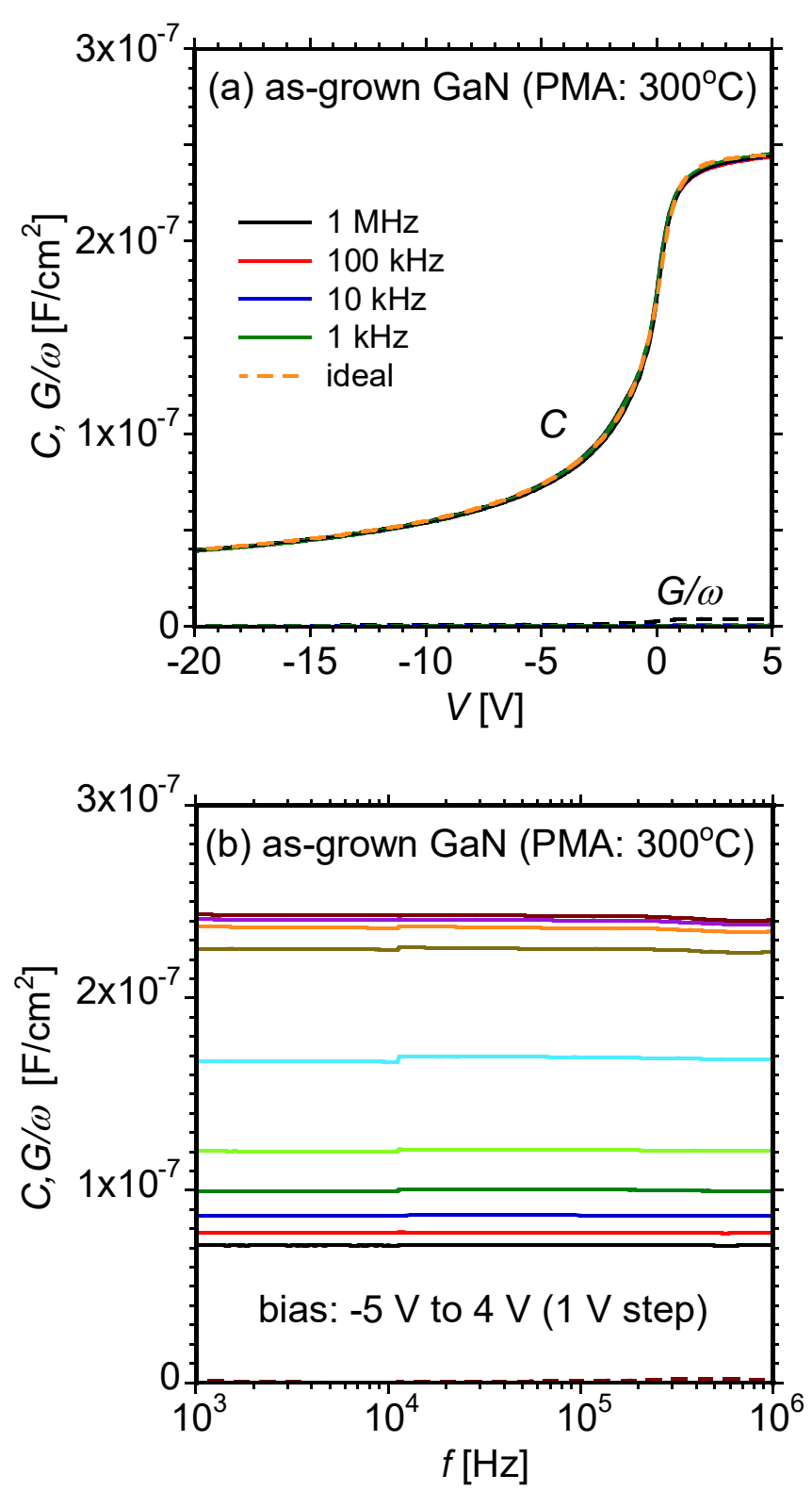

Figure 4. (a) $C-V$ and (b) $C-f$ characteristics for the MOS diode with as-grown GaN without Mg-ion implantation. 

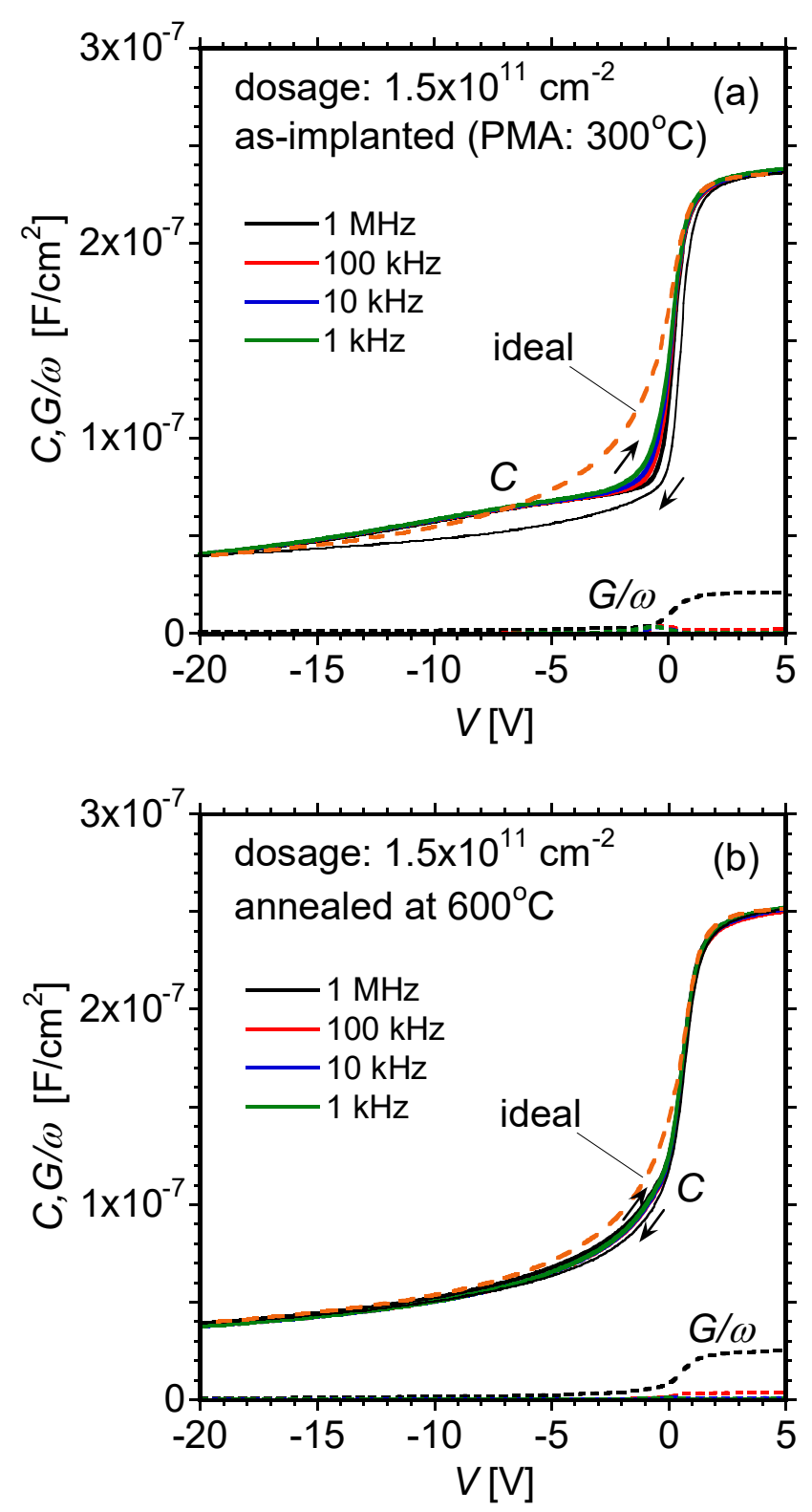

Figure 5. $C-V$ characteristics for the low-dosage sample: (a) without and (b) with $600{ }^{\circ} \mathrm{C}$ annealing. 

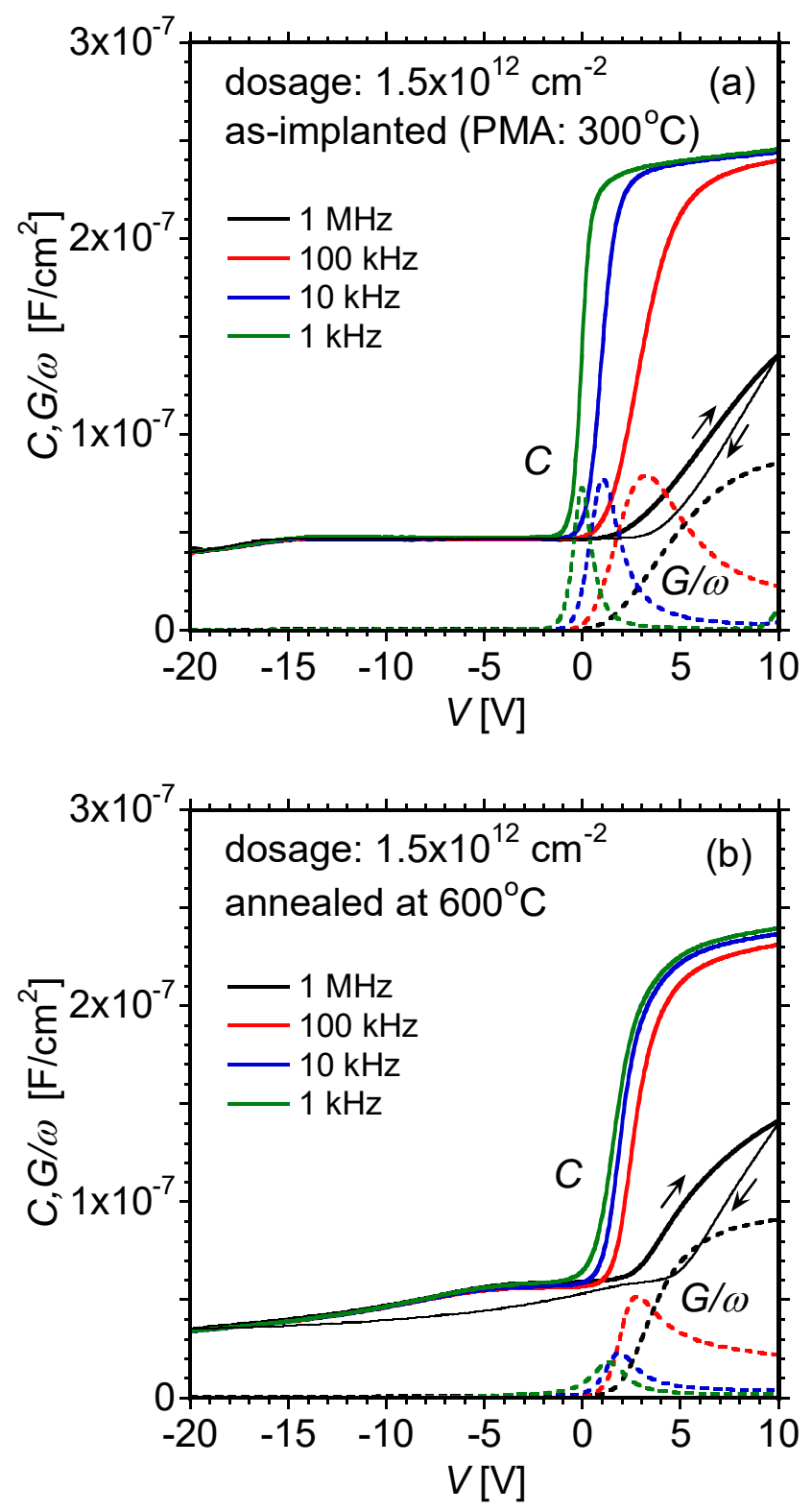

Figure 6. $C-V$ characteristics for the high-dosage sample: (a) without and (b) with $600{ }^{\circ} \mathrm{C}$ annealing. 

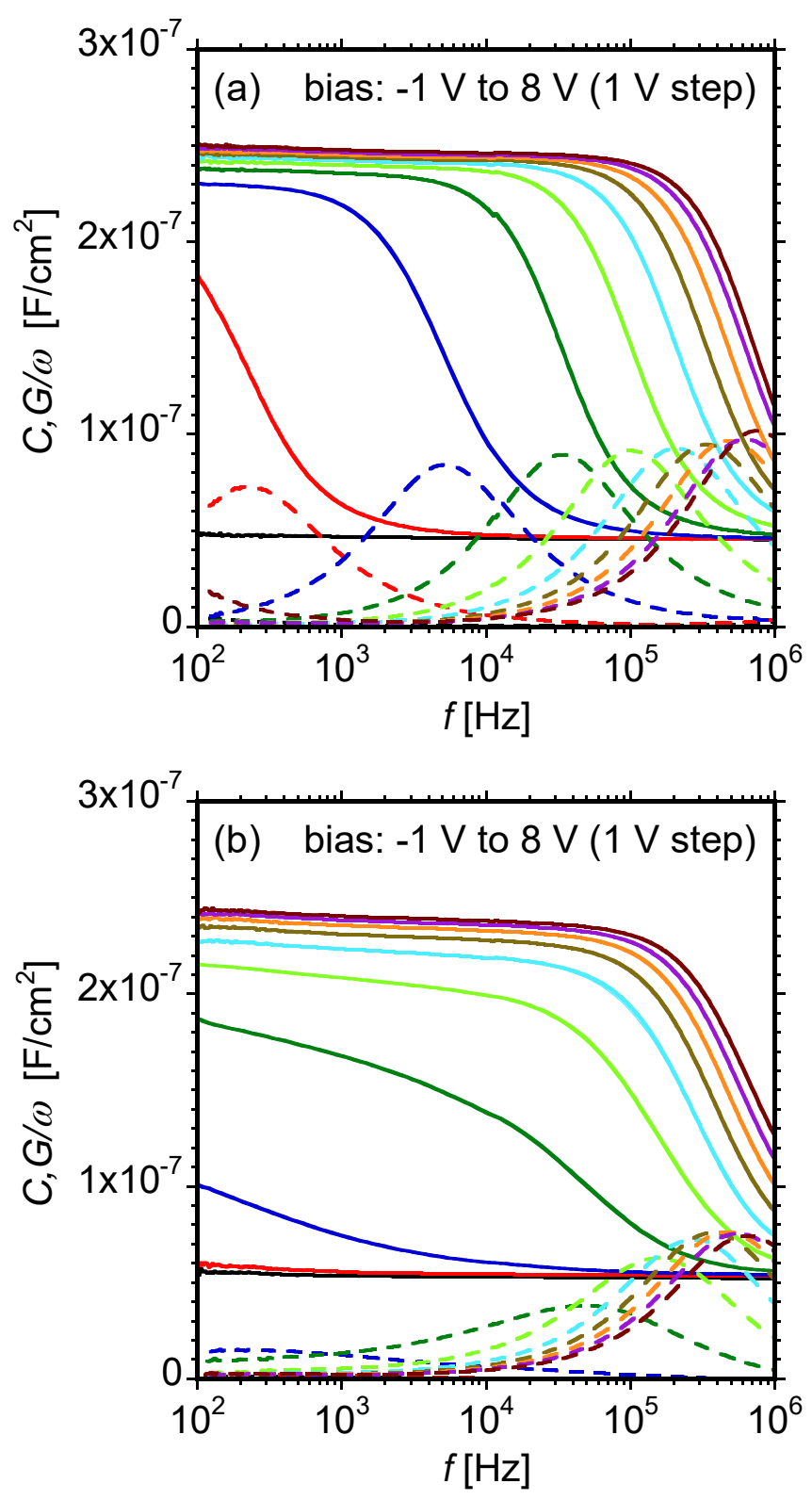

Figure 7. $C-f$ characteristics for the higher dosage sample: (a) without and (b) with $600{ }^{\circ} \mathrm{C}$ annealing. 

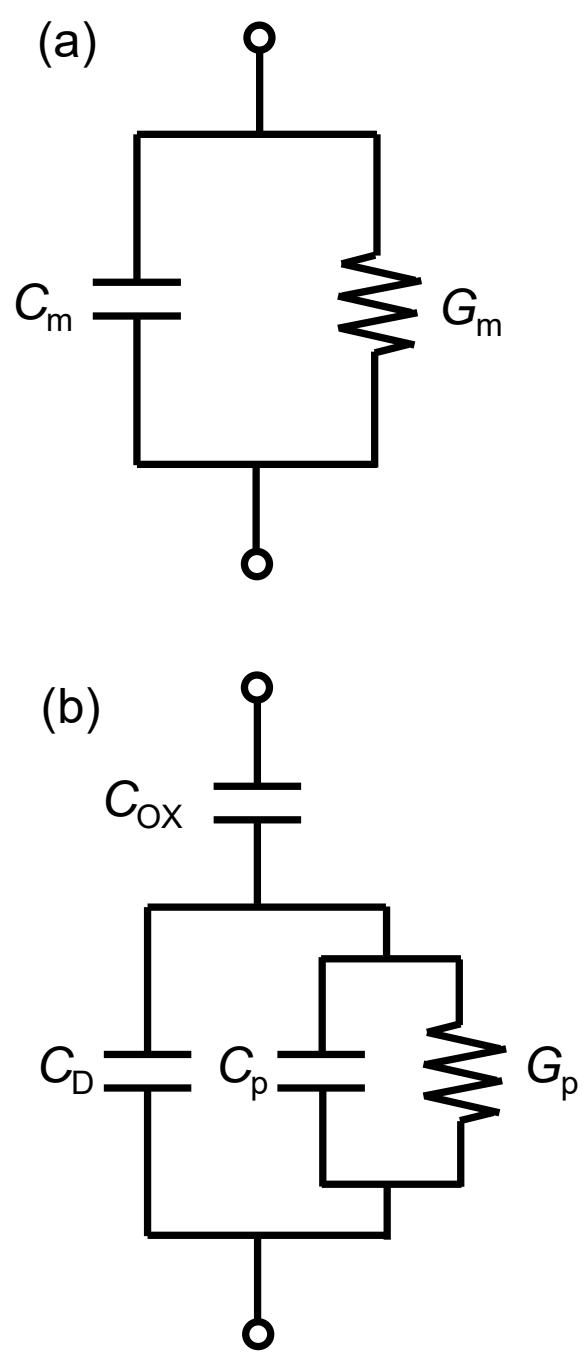

Figure 8. Equivalent circuits. (a) Circuit for measurement data. (b) Circuit for physical model of MOS diode including interface trap admittance. 

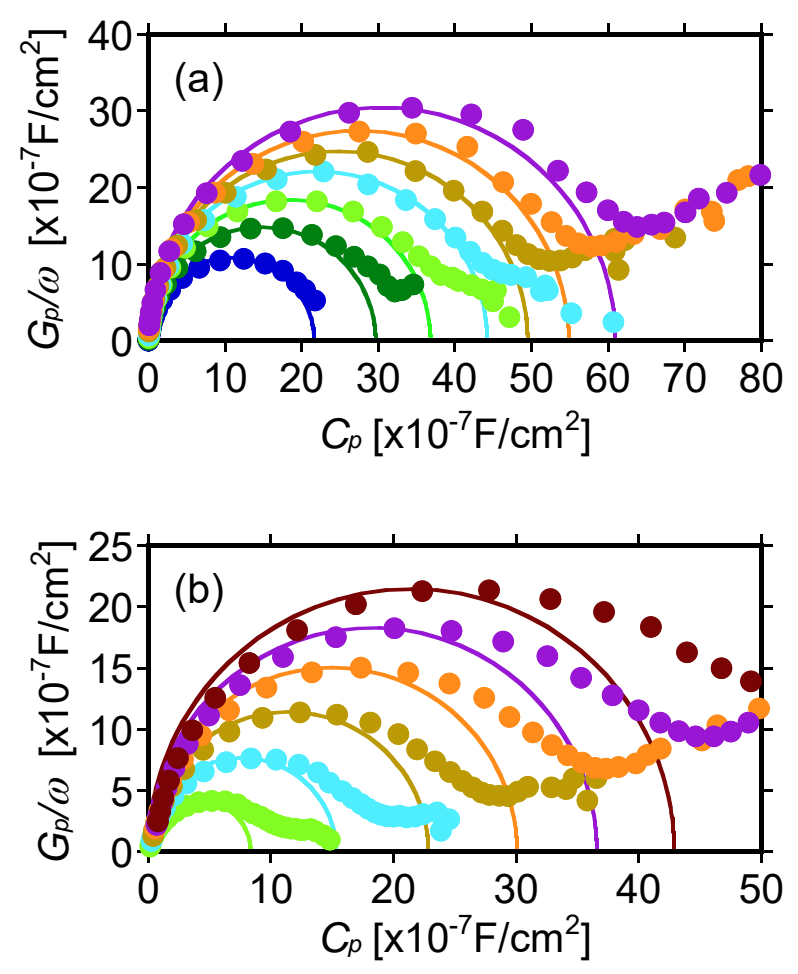

Figure 9. Cole-Cole diagrams for the high-dosage sample: (a) without and (b) with $600{ }^{\circ} \mathrm{C}$ annealing. The solid lines are fitting lines using Equation (6). 

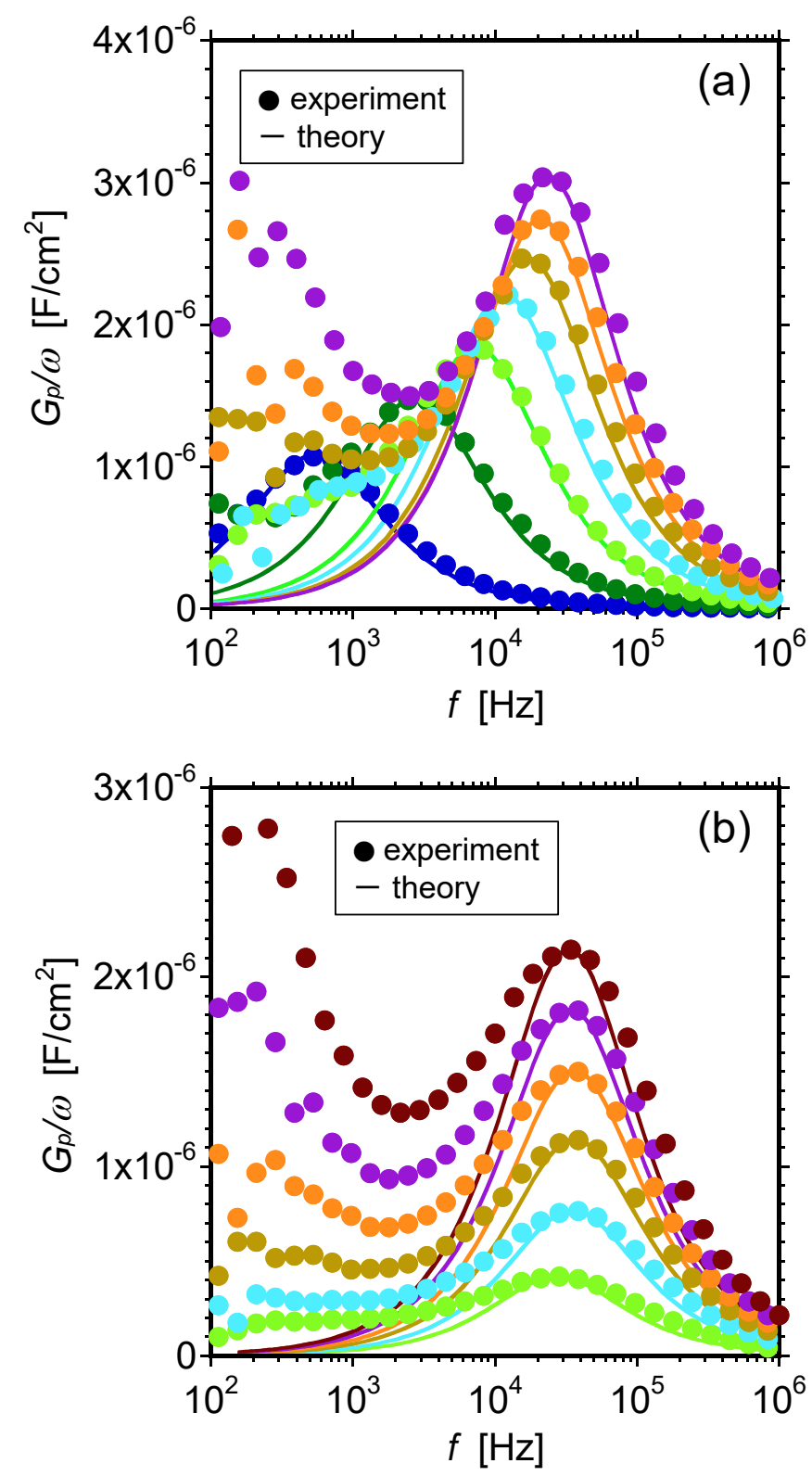

Figure 10. Calculated $G_{\mathrm{p}} / \omega$ for the high-dosage sample: (a) without and (b) with $600{ }^{\circ} \mathrm{C}$ annealing. The solid lines are fitting lines using Equation (5). 

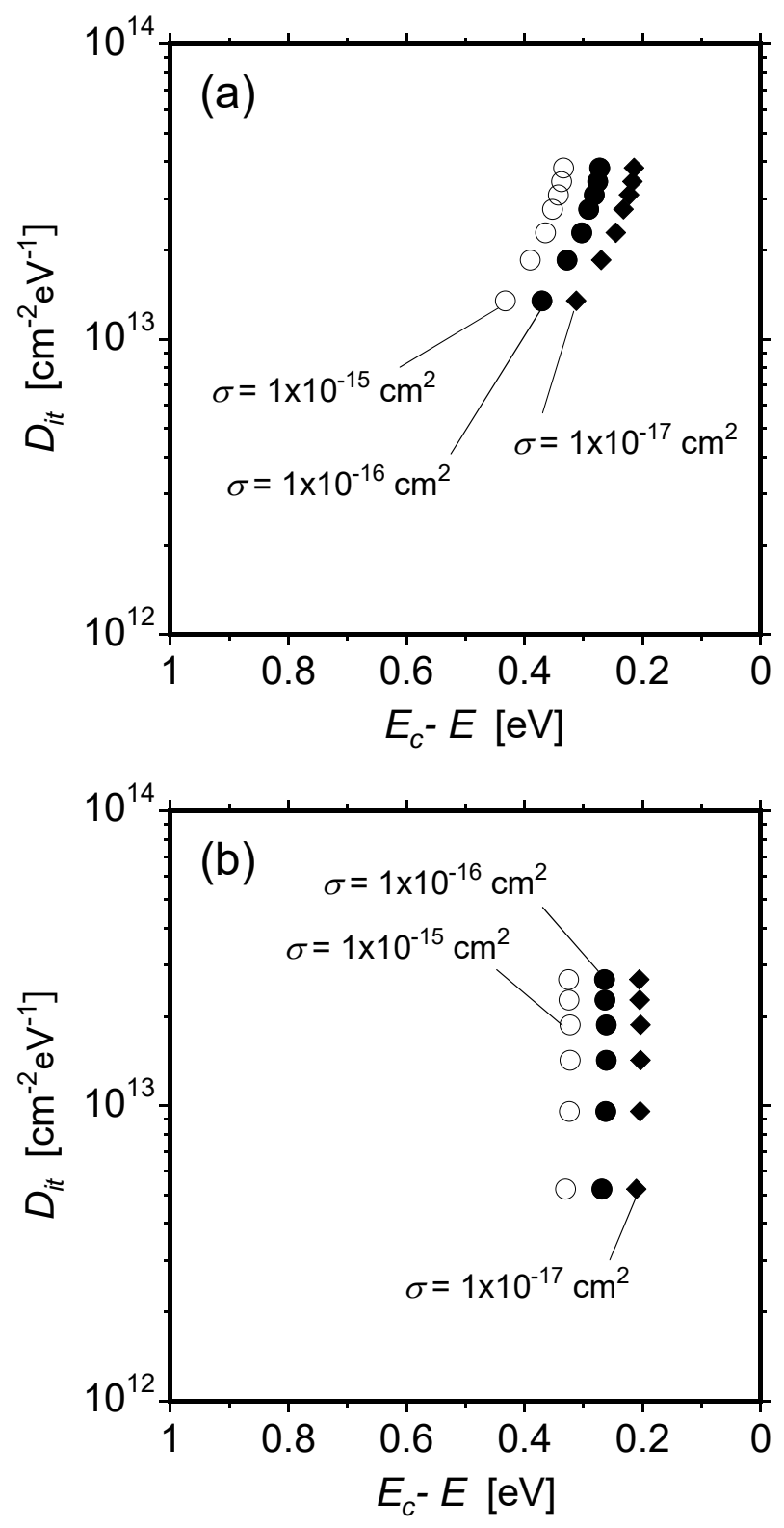

Figure 11. Calculated $D_{\text {it }}$ distributions for the high-dosage sample with three different $\sigma$ : (a) without and (b) with $600{ }^{\circ} \mathrm{C}$ annealing. 

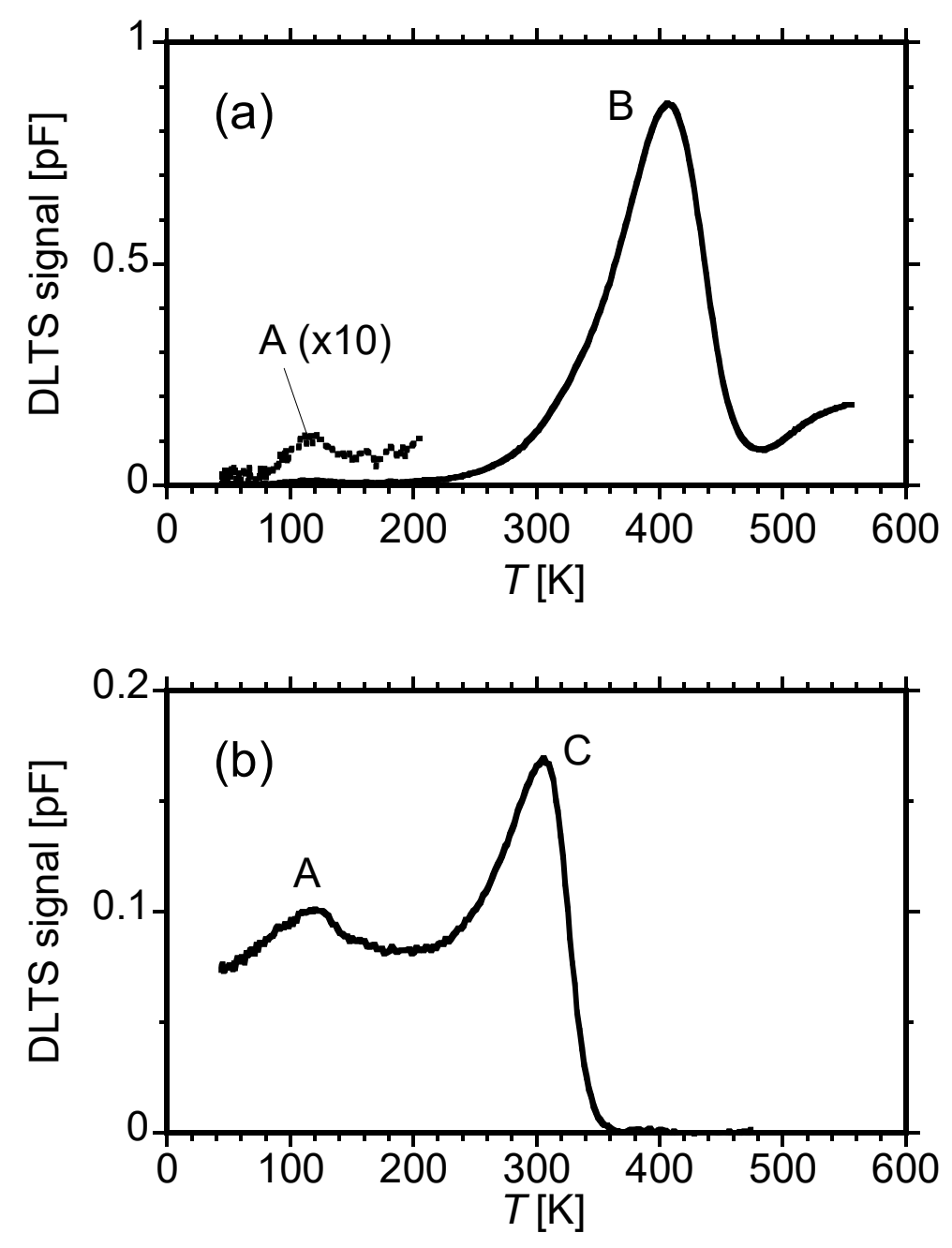

Figure 12. DLTS signals obtained for (a) the low-dosage sample and (b) the high-dosage sample. 


\section{WILEY-VCH}

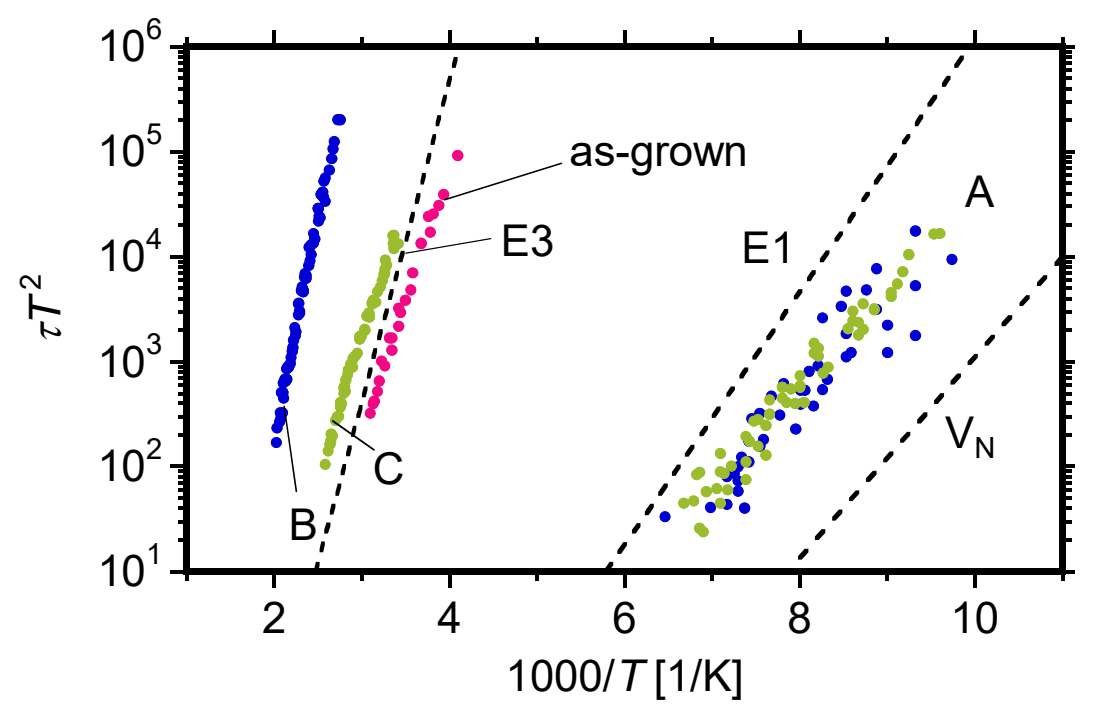

Figure 13. Arrhenius plots of detected deep levels. 